\title{
MicroRNA: A Major Key in Pain Neurobiology
}

\author{
Unda, Santiago R*, Villegas and Emilce A \\ Instituto de Biotecnología, Centro de Investigación e Innovación Tecnológica, Universidad Nacional de La Rioja, Argentina
}

Submission: September 19, 2017; Published: December 04, 2017

*Corresponding author: Santiago R, Instituto de Biotecnología, Centro de Investigación e Innovación Tecnológica, Universidad Nacional de La Rioja, Argentina. Av Luis Vernet y Apostol Felipe, 5300 La Rioja, Argentina, Av. Maipú 1367, La Rioja, Argentina, Tel: +54 3804277348;

Email: santiagounda94@gmail.com

\begin{abstract}
MiRNAs are single-stranded small noncoding RNAs that consist of approximately 22 nucleotides, that are involve in a wide range of biological processes including pain physiopathology. Because of their role as master switches in regulation and signaling pathways through modifications in nociceptive receptors, ion channels, pro-inflammatory molecules, emotional and cognitional behaviors associated with pain, the triggered enthusiasm for miRNAs as promising therapeutic targets is still active. Furthermore, the expression of specific miRNA can be helpful to predict treatment response in patients which suffer pain conditions that are poorly controlled by the currently available analgesics. This evidence is supported in several researches with animal pain models that we briefly review in this article to approximate in the understand of the role and neurobiology process through miRNA represents a major key for future therapeutics in pain, emphasizing in the neuropathic pain condition.
\end{abstract}

Keywords: MicroRNA; Neurobiology; Neuropathic pain

\section{Introduction}

Neuropathic pain (NP) represents one of main causes of chronic pain, perhaps trailing only osteoarthritis as a cause [1]. One of the keys to understand the biology of neuropathic pain is to know that's is caused by an injury in a nervous tissue and that nociceptive pathways are involve in the lesion [2]. In the clinical practice, the most frequent NP origins are the neurons of dorsal root ganglia (DRG) and trigeminal ganglia (TG) in mechanical, metabolic and toxic lesions as traumatic injury, herpes zoster, diabetes, or cancer chemotherapy, all this kind of pathologies promotes functional changes in the initiation and maintenance of NP $[3,4]$.

The several changes observed in neuropathic pain condition are well represented in two major symptoms, allodynia and hyperalgesia. Both symptoms are observed in patients and as signs in animal models of chronic pain such as the spinal nerve ligation (SNL), consisting in a tight ligation of L5 and L6 spinal nerves were Fukuoka et al. [5] described a down-regulation of the inhibitory $\gamma$-amino butyric acid receptor A (GABAA) in the dorsal root ganglia (DRG). In spared nerve injury (SNI) were shown an up-regulation of interleukin-1 $\beta$ (IL-1 $\beta$ ) in the prefrontal cortex of rats [6]. And many other changes can be observe in every pre-clinical model of pain which includes up-regulation of interleukin-6 (IL-6) [7], neurokinin-1 receptor in the dorsal horn [8], down regulation of dopaminergic D1 and D2 receptors in the anterior cingulate cortex in a rat model [9] just to mention a few. Clearly, this changes in the substances and receptors regulation are product of an altered gene expression in the nociceptive pathways. One of the most recent studied mechanisms that explains the pathogenesis and play a crucial role in fine-tuning gene expression [10] in the chronic pain is MicroRNAs (miRNAs) regulation, that are involve in a wide range of biological processes [11]. In this review we will focus in the role and neurobiology process through miRNA represents a major key for future therapeutics in pain, emphasizing in the NP condition.

\section{Biology and mechanisms of miRNA}

MiRNAs are single-stranded small noncoding RNAs that consist of approximately 22 nucleotides. The genomic location of miRNAs can be broadly divided into intergenic (between genes) or intronic (embedded into a gene) [11]. After the transcription of a coding DNA protein is expressed the precursor messenger RNA (pre-mRNA) which conformation includes 4 regions, $5^{\prime}$-untranslated region (UTR), the protein-coding exon, the noncoding intron, and the $3^{\prime}$-UTR, that determines the main targets of miRNA [12]. The intronic or intron-derived microRNA (Id-miRNA) is formed in the in-frame introns and the intergenic miRNAs are set between independent transcription units [13], both has the capability of degrading messenger-RNA (mRNA) and inhibit protein translation so they share not only functional but also structural properties. With the only difference that intronic miRNA are typically transcribed from the same promoter as their host genes (Pol II) and require RNA splicing machinery [14-16] while intergenic RNAs genes have their own transcription regulatory elements [13]. 


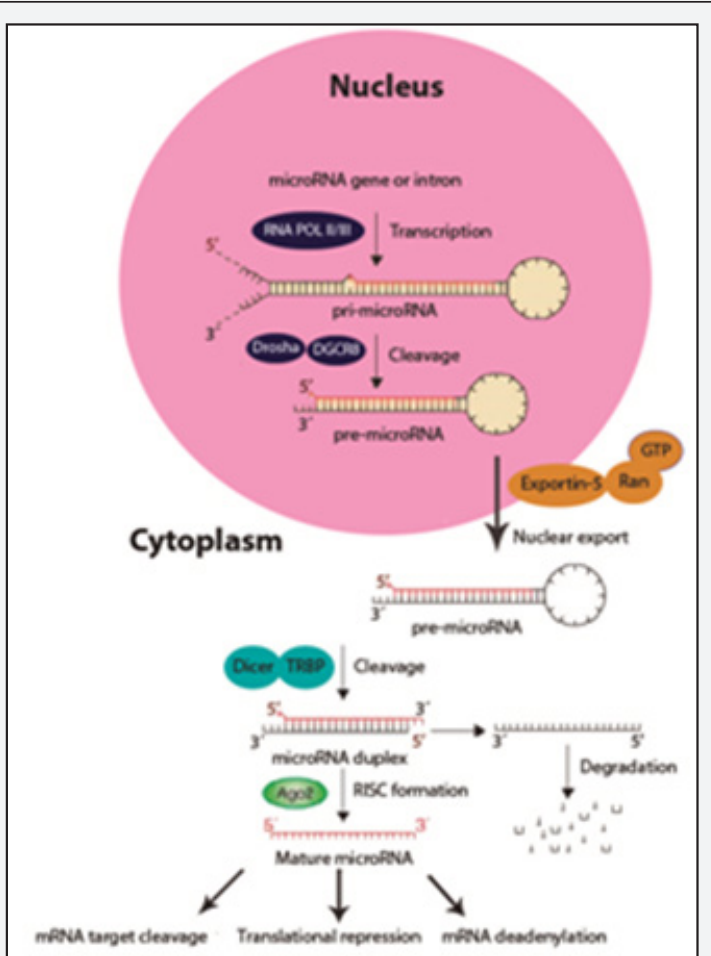

Figure 1: The linear processing pathway of miRNA. The formation of the RNA-induced gene silencing complex (RISC) is capable of executing RNA interference (RNAi)-related gene silencing, concluding in mRNA deadenylation, translational repression and mRNA cleavage.

In Figure 1 is represented the genesis and mechanism by which the interaction between miRNA, the target mRNA and the RNA-induced gene silencing complex (RISC) suppress the gene expression. This process begin with the excision of the primary precursor microRNA (pri-miRNA) by the RNA polymerase typeII (Pol-II) [17], this pri-miRNA at certain concentration can make a negative feedback to Pol-II. Then if the pri-miRNA is origin in an exon, it will be cropped into the hairpin-shaped pre-miRNAs by nuclear RNase III Drosha [18] or by spliceosomal components if comes from introns to form a mature precursor miRNA (premiRNA). This pre-miRNA is exported out of the nucleus to the cytoplasm by a member of a Ran-dependent nuclear transport receptor family, the exportin-5 (Exp5) [19] where is cleaved to the Dicer-like nucleases to form mature miRNA [20]. Finally the miRNA is coupled to a ribo nuclear particle (RNP) to get the RISC which is capable of executing RNA interference (RNAi)related gene silencing, concluding in the inhibition of the protein translation [21].

\section{MiRNA and Pain}

The comprehension of the extensive pathways involved in the genesis of pain put in evidence that the genetic basis play a major role in pain biology [22]. In the very last years the focus of researches have been in looking not in an specific target or individual receptor but instead in a "major switch" that would regulate multiple gene products and orchestrate multiple pathways [23] and the recent evidence propose miRNA to be that switch. The miRNAs have been implied in inflammation [24] process and other pain conditions such as neuropathic pain [25] and fibromyalgia [26]. This both common clinical problems are usually poorly controlled by the currently available analgesics [27], the reason might be the complex and multiple processing of nociceptive information in pathological conditions [28]. The changes in this processing are the cause of phenomes like hyperexcitability that can be induced by a posttranslational modulation of ion channels, such as voltage-gated sodium channels [29] or long term potentiation (LTP) and disinhibition that are product of synaptic modifications [30]. So, this phenomes initiated by altered processing in nociceptive pathways respond to certain structures like spinal glial cells, especially microglia and astrocytes that also plays a major role in pain modulation [31] and can be govern by epigenetic mechanisms such as DNA methylation, histone modification, and miRNA expressions [32].

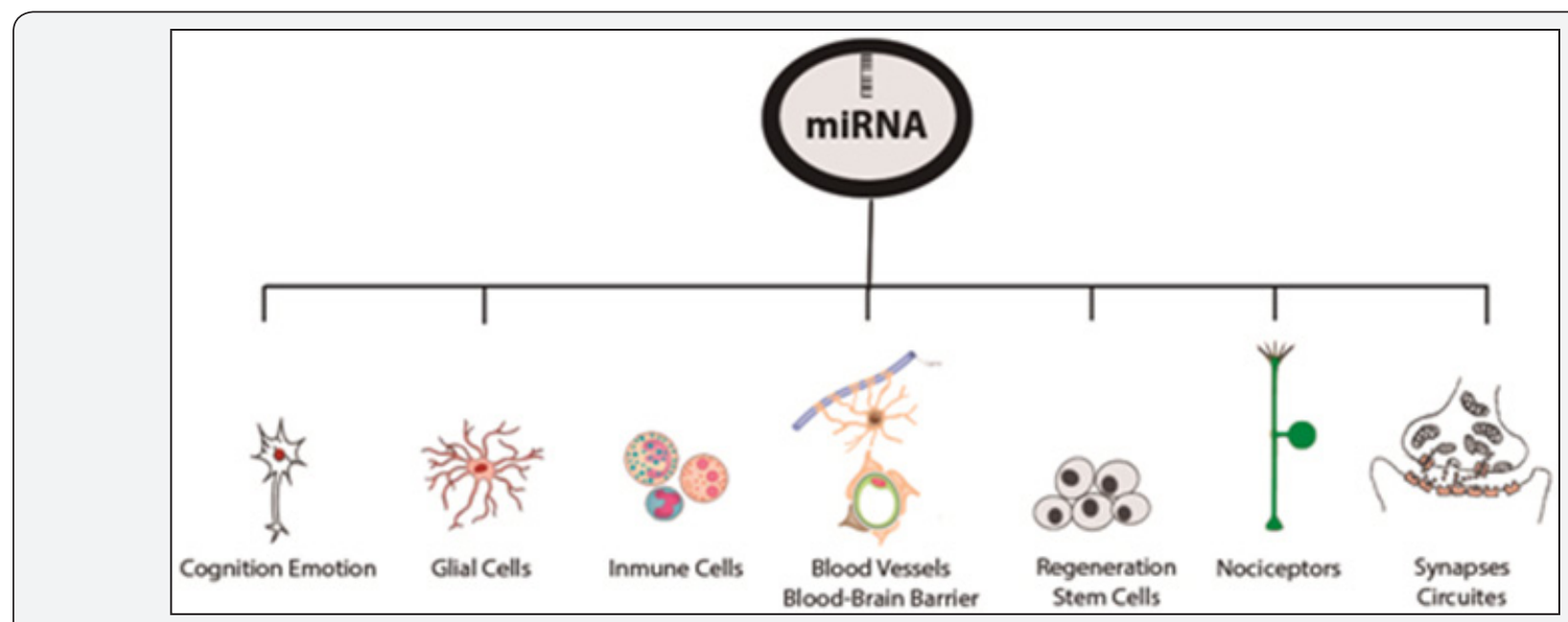

Figure 2 : miRNA plays a "major switch" role in many pathways involved in pain development and maintenance including behavioral, emotional and cognitional changes. 
This supports the evidence of the critical role of miRNAs in pain biology, but not only at molecular, network or synaptic level, the miRNAs are implied in behavioral, emotional and cognitional changes [33] that affects pain perception [34] (Figure 2). However, the expression of miRNAs in DRG, spinal cord, and brain regions such as the limbic system and prefrontal cortex can vary from the different causes of pain [4]. The Table Table 1: Characterized Non coding RNAs in various painful conditions.
1 , resumes some of the most representative miRNAs expressed in certain pathologies and animal model of acute and chronic pain, excluding neuropathic pain that will be considered in the next section. Figure 2. miRNA plays a "major switch" role in many pathways involved in pain development and maintenance including behavioral, emotional and cognitional changes.

\begin{tabular}{|c|c|c|c|c|}
\hline Model & ncRNAs & Expression & Tissue & Reference \\
\hline Formalin injection & miR-124a & Down & $\begin{array}{c}\text { Murine ipsilateral dorsal } \\
\text { horn neurons }\end{array}$ & Kynast et al. [35] \\
\hline & $\begin{array}{c}\text { miR-29a, -98,-99a, -124a, } \\
-134,-183 .\end{array}$ & Down & Rat ipsilateral trigeminal \\
ganglion & $\begin{array}{c}\text { Suzuki et al. [38] Bai et } \\
\text { al. [39] }\end{array}$ \\
\hline CFA & miR-1, -16, 206 & Down & $\begin{array}{c}\text { Rat ipsilateral DRG } \\
\text { neurons }\end{array}$ & Kusuda et al. [40] \\
\hline & miR-1,-16, 206 & Up & Rat ipsilateral spinal \\
dorsal horn neurons & Tam et al. [41] \\
\hline miR-143 & Down & Murine ipsilateral DRG & Pan et al. [42] \\
\hline Osteoarthritis & miR-219 & Down & Human chondrocytes & $\begin{array}{c}\text { Akhtar et al. [43] Park et } \\
\text { al. [44] }\end{array}$ \\
\hline Bone cancer & miR-146a & Down & Human Synoviocytes & Li et al. [45] \\
\hline
\end{tabular}

In the case of acute pain, the intra plantar formalin injection, was shown to decrease miR-124a expression in murine nociceptive spinal neurons in the ipsilateral horn [35], which importance seems to be related to the Methyl CpG binding protein 2 (MeCP2) a multifunctional epigenetic regulator that is best known for its role in the neurological disorders [36] and inflammatory pain [37]. Also, the tongue heat hyperalgesia following complete Freund's adjuvant (CFA) injection shown that MeCP2 is involved in regulation of the transient receptor potential vanilloid 1 (TRPV1) expression in TG neurons [38], supporting the evidence of the down regulation of miRNA124a for the expression of MeCP2. Other works revealed by a real-time reverse-transcription polymerase chain reaction (RTPCR) a significant, but differential, downregulation of mature miR-10a, -29a, -98, -99a, -124a, -134, and -183 in the ipsilateral mandibular division (V3) of the TG within 4hr after CFA [39], this down regulation of miRNA releases the translation inhibition of target mRNAs, thus yielding more proteins that may be relevant to the development and/or maintenance of inflammatory pain as Bai et al. [25] conclude. In 2011 Kusuda et al. [40] found that CFA-induced inflammation significantly reduced miRs-1-16 and -206 expression in DRG. Conversely, in the spinal dorsal horn all three miRNAs monitored were up regulated [40]. Tam et al. [41] demonstrate for the first time that miR-143 expression in DRG nociceptive neurons is declined in response to inflammation [41]. More recently, Pan et al. [42] using a CFA model concluded that methylation-mediated epigenetic modification of spinal miR-219 expression regulates chronic inflammatory pain by targeting calcium/calmodulin-dependent protein kinase II $\gamma$ (CaMKII $\gamma$ ) which regulates NMDAR signaling and central sensitization [42].

In human chondrocytes with IL-1 $\beta$ in vitro stimulation, revealed that the treatment with $\mathrm{p} 38$ - mitogen-activated protein kinase (MAPK) inhibitor (SB202190), enhanced the expression of miR-199a* which can directly target COX-2 mRNA and reduce protein expression levels [43]. Considering the IL-1 $\beta$ as a major mediator in chronic pain, described that miR-127-5p regulates MMP-13 expression and IL-1 $\beta$-induced catabolic responses in human chondrocytes too [44]. Finally, another miRNA, the miR-146a expressed at reduced levels in DRGs and dorsal horn of the spinal cords from rats with Osteoarthritis (OA)induced pain significantly modulates inflammatory cytokines and pain-related molecules (e.g. TNF $\alpha$, COX-2, iNOS, IL-6, IL8, RANTS and ion channel, TRPV1) [45]. In cancer-associated pain, another form of chronic pain, miR-1a-3p plays an important role attenuating the mechanical hypersensitivity [46], however in this pain condition, it might been implied a large list of miRs.

\section{Role and Expression of miRNAs in Neuropathic pain}

The role of miRNA in the regulation of nociception, endogenous analgesia and in the circuitries and cognitive, emotional and behavioral components involved in pain is expected to shed new light on the enigmatic pathophysiology of neuropathic pain [24]. Therefore disruption of miRNA processing in primary afferent pathways is sufficient to inhibit injury-induced long-term development of chronic pain-related behaviors, this affirmation is supported in a large evidence of investigations we resumed in Table 2 . 


\section{International Journal of Cell Science \& Molecular Biology}

Table 2: Characterized Noncoding RNAs in neuropathic pain condition.

\begin{tabular}{|c|c|c|c|c|}
\hline Model & ncRNAs & Expression & Tissue & Reference \\
\hline \multirow{9}{*}{ SCI } & miR-21 & Up & Spinal cord & Bhalala et al. [50] \\
\hline & & & & Strickland et al. [51] \\
\hline & miR-124a & Down & Spinal cord & Nakanishi et al. [53] \\
\hline & & & & Strickland et al. [52] \\
\hline & & & & Strickland et al. [51] \\
\hline & miR-223 & Up & Spinal cord & Nakanishi et al. [53] \\
\hline & $\operatorname{miR}-23 \mathrm{~b}$ & Down & Spinal cord & Im et al. [54] \\
\hline & miR-212 & Down & Spinal cord & Wang et al. [55] \\
\hline & miR-449a & Up & Spinal cord & Zhu et al. [56] \\
\hline \multirow{9}{*}{ SNL } & miR-7a, -21 & Down/Up & DRG & \\
\hline & & & & Sakai et al. [58] \\
\hline & & & & Suzuki [59] \\
\hline & miR-96, -182, -183 & Down & DRG & Aldrich et al. [60] \\
\hline & miR-103 & Down & Spinal Cord & Favereaux et al. [61] \\
\hline & miR-183 & Down & DRG & Lin et al. [62] \\
\hline & miR-195 & Up & Spinal cord & Shi et al. [63] \\
\hline & miR-30b & Up & DRG & Shao et al. [64] \\
\hline & & & & Su et al. [65] \\
\hline \multirow{5}{*}{ CCI } & miR-7a, -21 & Down/Up & DRG & $\begin{array}{c}\text { Sakai et al. [4], Sakai et } \\
\text { al. [38] }\end{array}$ \\
\hline & miR-539 & Down & Anterior cingulate cortex & Ding et al. [67] \\
\hline & miR-93 & Down & Spinal cord & Yan et al. [68] \\
\hline & miR-183 & Down & Spinal dorsal horn & Xie et al. [69] \\
\hline & miR-145 & Down & Spinal cord & Pang et al. [70] \\
\hline Bilateral CCI & miR-203 & Down & Spinal cord & Li et al. [71] \\
\hline Axotomy & miR-21, -222 & Up & DRG & Zhou, et al. [72] \\
\hline \multirow{2}{*}{ Nerve crush } & miR-21, -142-5p, -221 & Up & Sciatic nerve & Wu et al. [73] \\
\hline & miR-124a & Down & Sciatic nerve & \\
\hline
\end{tabular}

NcRNA (Noncoding RNA), SCI (Spinal cord injury), SNL (Spinal nerve ligation), CCl (Chronic constriction injury).

To start explaining the role of miRNA in neuropathic pain, let's first mention some of the main animal models that have been development in this area. First the spinal cord injury (SCI) was proposed by Allen AR in 1911 [47] then in [48], adapted the Allen`s method by a briefly laminectomy performed at the T910 thoracic vertebrae level to expose the spinal cord at T10 and inducing the SCI by New York University Impactor device [49], with this methods it has been possible to correlate the injury of the spinal cord with the regulation and expression of miRs like miR-21, miR-124a, miR-23b, miR-223, miR-449a and miR212 [50-56]. Spinal nerve ligation (SNL), the left L6 transverse process is removed to expose the L4 and L5 spinal nerves then the L5 spinal nerve is carefully isolated, tightly ligated with 3-0 silk thread, and transected just distal to the ligature [57], with this method it's has been studied the miRs miR-7a, -21, -96, $-182,-183,-103,-195$ [58-63] and more recently with miARN30b $[64,65]$. The chronic constriction injury (CCI) model was proposed by Bennett and Xie in 1988 [66], in this model the right sciatic nerve is tied loosely with four ligatures by chromic cat gut 4-0, the lastly works with this method revealed the expression of miR-7a, -21, -539, -93, -183, -145 and -203 [58,59,67-71]. The axotomy model consist in a transection of the sciatic nerve at a point approximately $1 \mathrm{~cm}$ distal to the exit point of spinal nerve roots, after Axotomy the expression of miR-21 and miR222 increased in DRG [72]. Finally, the Nerve crush model is achieved after expose sciatic nerve and crush in the mid-thigh for $15 \mathrm{sec}$ with a fine hemostat, in the day 4 and 7 post injury the three most highly up regulated miRNAs was miR-21, miR142-5p, and miR-221 [73]. Now we'll mention some of the most representative and lastly found miR`s involved in neuropathic pain development.

The miR-21 is expressed in all the neuropathic pain models, [54] demonstrated that miR-21 transcripts are physiologically regulated by peripheral nerve injury. Their role appeared to be enhance neurite outgrowth from DRG neurons by targeting 
the Sprouty2 protein (SPRY2) 3' UTR region in rats after axotomy. More recently, [69] studied the role of miR-183 in the development of neuropathic pain using the CCI model they revealed that miR-183 can suppress AMPA receptors by inhibiting the mammalian target of rapamycin (mTOR)/ vascular endothelial growth factor (VEGF) pathway, which alleviates the mechanical hypersensitivity associated with inflammation and neuropathy [74]. Shao et al. [64] evidenced that one of the major targets in neuropathic pain, the voltage-gated sodium channel Nav1.7 are directly target by miR-30b. The expression of Nav 1.7 increases in nociceptive neurons during the development of inflammatory hyperalgesia, while the knockdown or ablation of Nav1.7 expression relieves inflammatory pain and hyperalgesia [75]. Finally, [70] study suggested that miR-145 serves an important role in the development of neuropathic pain through regulating RREB1 expression and the PI3K/AKT signaling pathway which serves an important role in vascular endothelial growth factor (VEGF)-induced hyperalgesia [76].

\section{Future Approaches and Conclusion}

The studies reviewed in this article may us consider the microRNA`s as potential targets and biomarkers for prediction and treatment of several pain conditions. Because of their role as master switches in regulation and signaling pathways through modifications in nociceptive receptors, ion channels, pro-inflammatory molecules, emotional and cognitional behaviors associated with pain, the triggered enthusiasm for miRNAs as promising therapeutic targets is still active. However, challenges with respect to the use of miRNA-based therapeutics in humans remain to be further explored [77]. When we can fully understand the role of miRNAs in pain mechanisms, it will be possible to maximize miRNAs potency while minimizing off target toxicity and immunogenicity to provide great benefit for clinical diagnostic and therapeutic applications.

\section{Acknowledgement}

Dr. Carlos H. Laino is greatly acknowledged for his help in the critical review of this work.

\section{References}

1. Campbell J, Meyer R (2006) Mechanisms of Neuropathic Pain. Neuron 52(1): 77-92.

2. Boivie J, Leijon G, Johansson I (1989) Central post-stroke pain-a study of the mechanisms through analyses of the sensory abnormalities. Pain 37(2): 173-185.

3. Devor M (2006) Sodium channels and mechanisms of neuropathic pain. J Pain 7(1): S3-S12.

4. Sakai A, Susuki H (2015) MicroRNA and Pain. Medical Evidence. Advances in Experimental Medicine and Biology. G Santulli (Ed.), Switzerland 888: 17-39.

5. Fukuoka T, Tokunaga A, Kondo E, Miki K, Tachibana T, et al. (1998) Change in mRNAs for neuropeptides and the GABA(A) receptor in dorsal root ganglion neurons in a rat experimental neuropathic pain model. Pain 78(1): 13-26.
6. Apkarian A, Lavarello S, Randolf A, Berra H, Chialvo D, et al. (2006) Expression of IL-1beta in supraspinal brain regions in rats with neuropathic pain. Neurosci Lett 407(2): 176-181.

7. Galán AI, Serrano-Muñoz D, Gómez SJ, Goicoechea C, Taylor J, et al. (2017) The role of Omega-3 and Omega-9 fatty acids for the treatment of neuropathic pain after neurotrauma. Biochim Biophys Acta 1859(9 Pt B): 1629-1635.

8. Taylor B, McCarson K (2004) Neurokinin-1 receptor gene expression in the mouse dorsal horn increases with neuropathic pain. J Pain 5(2): 71-76.

9. Ortega LJ, Gortari P, De Garduno GR, Amaya MI, Leon OM, et al. (2011) Expression of the dopaminergic D1 and D2 receptors in the anterior cingulate cortex in a model of neuropathic pain. Mol Pain 7: 97.

10. Bartel D (2009) MicroRNAs: target recognition and regulatory functions. Cell 136(2): 215-233.

11. McDonald MK, Ajit SK (2015) MicroRNA Biology and Pain. Progress in Molecular Biology and Translational Science 131(8): 215-249.

12. Lin S, Miller J, Ying S (2006) Intronic MicroRNA (miRNA). Journal of Biomedicine and Biotechnology 2006(4): 26818.

13. Monteys A, Spengler R, Wan J, Tecedor L, Lennox K, et al. (2010) Structure and activity of putative intronic miRNA promoters. RNA 16(3): 495-505.

14. Lin SL, Chang D, Wu DY, Ying SY (2003) A novel RNA splicing-mediated gene silencing mechanism potential for genome evolution. Biochemical and Biophysical Research Communications 310(3): 754-760.

15. Lin SL, Chuong CM, Ying SY (2001) A novel mRNA-cDNA interference phenomenon for silencing bcl-2 expression in human LNCaP cells. Biochem Biophys Res Commun 281(3): 639-644.

16. Ying SY, Lin SL (2004) Intron-derived microRNAs-fine tuning of gene functions. Gene 342(1): 25-28.

17. Lee Y, Kim M, Han J, Yeom KH, Lee S, et al. (2004) MicroRNA genes are transcribed by RNA polymerase II. EMBO Journal 23(20): 4051-4060.

18. Kim VN (2004) MicroRNA precursors in motion: exportin-5 mediates their nuclear export. Trends Cell Biol 14(4): 156-159.

19. Lund E, Güttinger S, Calado A, Dahlberg JE, Kutay U (2004) Nuclear export of microRNA precursors. Science 303(5654): 95-98.

20. Luo X, Yang B, Nattel S (2015) MicroRNAs and atrial fibrillation: mechanisms and translational potential. Nat Rev Cardiol 12(2): 80-90.

21. Jagtap UB, Gurav RG, Bapat VA (2011) Role of RNA interference in plant improvement. Naturwissen schaften 98(6): 473-492.

22. Bhalala OG, Srikanth M, Kessler JA (2013) The emerging roles of microRNAs in CNS injuries. Nat Rev Neurol 9(6): 328-339.

23. Sommer C (2016) Exploring pain pathophysiology in patients. Science 354(6312): 588-592.

24. Kress M, Hüttenhofer A, Landry M, Kuner R, Favereaux A, et al. (2013) microRNAs in nociceptive circuits as predictors of future clinical applications. Front Mol Neurosci 6: 33.

25. Bali KK, Hackenberg M, Lubin A, Kuner R, Devor M (2014) Sources of individual variability: miRNAs that predispose to neuropathic pain identified using genome-wide sequencing. Mol Pain 10: 22.

26. Cerdá OG, Mena-Durán AV, Monsalve V, Oltra E (2015) Identification of a microRNA signature for the diagnosis of fibromialgia. PLoS One 10(3): e0121903.

27. Dworkin RH, O'Connor AB, Kent J, Mackey SC, Raja SN, et al. (2013) Interventional management of neuropathic pain: NeuPSIG recommendations. Pain 154(11): 2249-2261. 
28. Prescott SA, Ma Q, De Koninck Y (2014) Normal and abnormal coding of somatosensory stimuli causing pain. Nat Neurosci 17(2): 183-191.

29. Waxman SG, Zamponi GW (2014) Regulating excitability of peripheral afferents: emerging ion channel targets. Nat Neurosci 17(2): 153-163.

30. Nickel FT, Seifert F, Lanz S, Maihöfner C (2012) Mechanisms of neuropathic pain. Eur Neuropsychopharmacol 22(2): 81-91.

31. Ji RR, Berta T, Nedergaard M (2013) Glia and pain: is chronic pain a gliopathy? Pain 154(1): S10-S28.

32. Descalzi G, Ikegami D, Ushijima T, Nestler EJ, Zachariou V, et al. (2015) Epigenetic mechanisms of chronic pain. Trends Neurosci 38(4): $237-$ 246

33. O'Connor R, Dinan T, Cryan J (2012) Little things on which happiness depends: microRNAs as novel therapeutic targets for the treatment of axiety and depression. Mol Psychiatry 17(4): 359-376.

34. Bushnell MC, Čeko M, Low LA (2013) Cognitive and emotional control of pain and its disruption in chronic pain. Nat Rev Neurosci 14(7): 502511.

35. Kynast K, Russe O, Möser C, Geisslinger G, Niederberger E (2013) Modulation of central nervous system-specifi c microRNA-124a alters the inflammatory response in the formalin test in mice. Pain 154(3): 368-376.

36. Jiang S, Li C, McRae G, , Lykken E, Sevilla J, et al. (2014) MeCP2 Reinforces STAT3 Signaling and the Generation of Effector CD4+ T Cells by Promoting miR-124-Mediated Suppression of SOCS5. Science signaling 7(316): ra25.

37. Géranton SM, Morenilla PC, Hunt SP (2007) A role for transcriptional repressor methyl-CpGbinding protein 2 and plasticity-related gene serum- and glucocorticoid-inducible kinase 1 in the induction of infl ammatory pain states. J Neurosci 27(23): 6163-6173.

38. Suzuki A, Shinoda M, Honda K, Shirakawa T, Iwata K (2016) Regulation of transient receptor potential vanilloid 1 expression in trigeminal ganglion neurons via methyl-CpG binding protein 2 signaling contributes tongue heat sensitivity and inflammatory hyperalgesia in mice. Mol Pain 12:1744806916633206.

39. Bai G, Ambalavanar R, Wei D, Dessem D (2007) Downregulation of selective microRNAs in trigeminal ganglion neurons following inflammatory muscle pain. Mol Pain 3: 15 .

40. Kusuda R, Cadetti F, Ravanelli MI, Sousa TA, Zanon S, et al. (2011) Differential expression of microRNAs in mouse pain models. Mol Pain 7: 17 .

41. Tam S, Bastian I, Zhou X, Vander H, Michael M, et al. (2011) MicroRNA-143 expression in dorsal root ganglion neurons. Cell Tissue Res 346(2): 163-173.

42. Pan Z, Zhu LJ, Li YQ, Hao LY, Yin C, et al. (2014) Epigenetic modification of spinal miR-219 expression regulates chronic inflammation pain by targeting CaMKII $\gamma$. J Neurosci 34(29): 9476-9483.

43. Akhtar N, Haqqi TM (2012) MicroRNA-199a* regulates the expression of cyclooxygenase-2 in human chondrocytes. Ann Rheum Dis 71(6): 1073-1080.

44. Park S, Cheon E, Lee M, Kim H (2013) MicroRNA-127-5p Regulates Matrix Metalloproteinase 13 Expression and Interleukin-1 $\beta$-Induced Catabolic Effects in Human Chondrocytes. Arthritis \& Rheumatism 65(12): 3141-3152

45. Li X, Gibson G, Kim JS, Kroin J, Xu S, et al. (2011) MicroRNA-146a is linked to Pain-related Pathophysiology of Osteoarthritis. Gene 480(12): 34-41.

46. Bali KK, Selvaraj D, Satagopam VP, Lu J, Schneider R, et al. (2013) Genome-wide identification and functional analyses of microRNA signatures associated with cancer pain. EMBO Mol Med 5(11): 1740 1758

47. Allen AR (1911) Surgery of experimental lesion of spinal cord equivalent to crush injury of fracture dislocation of spinal column. Preliminary report Jama 57(11): 878-880.

48. Koozekanani SH, Vise WM, Hashemi RM, McGhee RB (1976) Possible mechanisms for observed pathophysiological variability in experimental spinal cord injury by the method of Allen. J Neurosurg 44(4): 429-434

49. Hao J, Li B, Duan H, Zhao CX, Zhang Y, et al. (2017) Mechanisms underlying the promotion of functional recovery by deferoxamine after spinal cord injury in rats. Neural Regen Res 12(6): 959-968.

50. Bhalala OG, Srikanth M, Kessler JA (2013) The emerging roles of microRNAs in CNS injuries. Nat Rev Neurol 9(6): 328-339.

51. Strickland ER, Woller SA, Garraway SM, Hook MA, Grau JW, et al. (2014) Regulatory effects of intermittent noxious stimulation on spinal cord injury-sensitive microRNAs and their presumptive targets following spinal cord contusion. Front in Neural Circuits 8: 117.

52. Strickland ER, Hook MA, Balaraman S, Huie JR, Grau JW, et al. (2011) MicroRNA dysregulation following spinal cord contusion: implications for neural plasticity and repair. Neuroscience 186: 146-160.

53. Nakanishi K, Nakasa T, Tanaka N, Ishikawa M, Yamada K, et al. (2010) Responses of microRNAs 124a and 223 following spinal cord injury in mice. Spinal Cord 48(3): 192-196.

54. Im YB, Jee MK, Jung JS, Choi JI, Jang JH, et al. (2012) miR23b ameliorates neuropathic pain in spinal cord by silencing NADPH oxidase 4. Antioxid Redox Signal 16(10): 1046-1060.

55. Wang CY, Deneen B, Tzeng SF (2017) MicroRNA-212 inhibits oligodendrocytes during maturation by down regulation of differentiation-associated gene expression. J Neurochem 143(1): 112125 .

56. Zhu Y, Wu Y, Zhang R (2017) Electro-acupuncture promotes the proliferation of neural stem cells and the survival of neurons by down regulating miR-449a in rat with spinal cord injury. EXCLI J 16: 363-374.

57. Fan L, Guan X, Wang W, Zhao JY, Zhang H, et al. (2014) Impaired neuropathic pain and preserved acute pain in rats overexpressing voltage-gated potassium channel subunit Kv1.2 in primary afferent neurons. Mol Pain 10: 8

58. Sakai A, Saitow F, Miyake N, Miyake K, Shimada T, et al. (2013) miR-7a alleviates the maintenance of neuropathic pain through regulation of neuronal excitability. Brain 136(9): 2738-2750.

59. Sakai A, Suzuki H (2013) Nerve injury-induced upregulation of miR21 in the primary sensory neurons contributes to neuropathic pain in rats. Biochem Biophys Res Commun 435(2):176-181.

60. Aldrich BT, Frakes EP, Kasuya J, Hammond DL, Kitamoto T (2009) Changes in expression of sensory organ-specific microRNAs in rat dorsal root ganglia in association with mechanical hypersensitivity induced by spinal nerve ligation. Neuroscience 164(2): 711-723.

61. Favereaux A, Thoumine O, Bouali BR, Roques V, Papon MA, et al. (2011) Bidirectional integrative regulation of Cav1.2 calcium channel by microRNA miR-103: role in pain. The EMBO Journal 30(18): 38303841.

62. Lin C, Chen K, Yang C, Huang H, Sheen-Chen SM (2014) Intrathecal miR183 delivery suppresses mechanical allodynia in mononeuropathic rats. Eur J Neurosci 39(10): 1682-1689.

63. Shi G, Shi J, Liu K, Liu N, Wang Y, et al. (2013) Increased miR-195 aggravates neuropathic pain by inhibiting autophagy following peripheral nerve injury. Glia 61(4): 504-512. 
64. Shao J, Cao J, Wang J, Ren X, Su S, et al. (2016) MicroRNA-30b regulates expression of the sodium channel Nav1.7 in nerve injury-induced neuropathic pain in the rat. Mol Pain 12: 1744806916671523.

65. Su S, Shao J, Zhao Q, Ren X, Cai W, et al. (2017) MiR-30b Attenuates Neuropathic Pain by Regulating Voltage-Gated Sodium Channel Nav1.3 in Rats. Front Mol Neurosci 10: 126.

66. Bennett GJ, Xie Y (1988) A peripheral mononeuropathy in rat that produces disorders of pain sensation like those seen in man. Pain 33(1): 87-107.

67. Ding M, Shen W, Hu Y (2017) The Role of miR-539 in the Anterior Cingulate Cortex in Chronic Neuropathic Pain. Pain Med

68. Yan XT, Ji LJ, Wang Z, Wu X, Wang Q, et al. (2017) MicroRNA-93 alleviates neuropathic pain through targeting signal transducer and activator of transcription 3. Int Immuno pharmacol 46: 156-162.

69. Xie X, Ma L, Xi K, Zhang W, Fan D (2017) MicroRNA-183 Suppresses Neuropathic Pain and Expression of AMPA Receptors by Targeting mTOR/VEGF Signaling Pathway. Cell Physiol Biochem 41(1): 181-192.

70. Pang X, Tang Y, Zhang D (2016) Role of miR-145 in chronic constriction injury in rats. Exp Ther Med 12(6): 4121-4127.

71. Li H, Huang Y, Ma C, Yu X, Zhang Z, et al. (2015) MiR-203 involves in neuropathic pain development and represses Rap1a expression in nerve growth factor differentiated neuronal PC12 cells. Clin J Pain 31(1): 36-43.

72. Zhou S, Zhang S, Wang Y, Yi S, Zhao L, et al. (2015) miR-21 and miR-222 inhibit apoptosis of adult dorsal root ganglion neurons by repressing TIMP3 following sciatic nerve injury. Neurosci Lett 586: 43-49.

73. Wu D, Raafat M, Pak E, Hammond S, Murashov AK (2011) MicroRNA machinery responds to peripheral nerve lesion in an injury-regulated pattern. Neuroscience 190: 386-397.

74. Obara I, Tochiki K, Geranton S, Carr F, Lumb B, et al. (2011) Systemic inhibition of the mammalian target of rapamycin (mTOR) pathway reduces neuropathic pain in mice. Pain 152(11): 2582-2595.

75. Minett M, Nassar M, Clark A, Passmore G, Dickenson AH, et al. (2012) Distinct Nav1.7-dependent pain sensations require different sets of sensory and sympathetic neurons. Nat Commun 3: 791.

76. Stein AT, UfretVC, Hua L, Santana LF, Gordon SE (2006) Phosphoinositide 3-kinase binds to TRPV1 and mediates NGF-stimulated TRPV1 trafficking to the plasma membrane. J Gen Physiol 128(5): 509-522.

77. Tan P, Pao Y, Cheng J, Hung K, Liu C (2013) MicroRNA-based therapy in pain medicine: Current progress and future prospects. Acta Anaesthesiol Taiwan 51 (4): 171-176.

Your next submission with Juniper Publishers will reach you the below assets

- Quality Editorial service

- Swift Peer Review

- Reprints availability

- E-prints Service

- Manuscript Podcast for convenient understanding

- Global attainment for your research

- Manuscript accessibility in different formats

( Pdf, E-pub, Full Text, Audio)

- Unceasing customer service

Track the below URL for one-step submission https://juniperpublishers.com/online-submission.php 